\title{
A impossível simbolização "daquilo que foi"
}

\author{
JACQUES LEENHARDT
}

RESUIMO: O autor aborda a cena artística francesa após a II Guerra Mundial a partir de uma idéia básica: por várias ordens de razões, foi impossível à cultura francesa realizar o "trabalho de luto" das vítimas do nazismo. Orientado por essa hipótese, o autor examina obras que tematizam a vida, a morte, a violência, a memória e o esquecimento. Impossibilitada de condensar a memória do horror no ritual e no monumento, a arte, após Auschwitz, pode apenas formular questões, tais como a da reversibilidade dos papéis do artista e do espectador e a da necessidade histórica de uma memória viva depois da violência escandalosa, assimbólica, inominável.

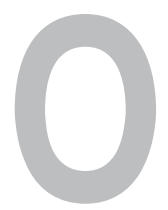

s seis anos de duração da Segunda Guerra Mundial não constituíram na França, no domínio da arte, um corte absoluto. É certo que o país estava ocupado, os sofrimentos econômicos e políticos abatem-se sobre todos, as exceções e as deportações enlutam as famílias e o racismo, importado ou espontâneo, semeia seus germes nocivos. Tudo isso faz desses anos um momento trágico.

Sob a férula do Kunstschutz1, que esvaziou os museus, exropriou as galerias e as coleções privadas de origem judia, impôs uma estética da qual Arno Brecker tornou-se o símbolo, queimou alguns Mirós, Picassos, a França artística dividiu-se em duas, alguns que fazem aliança com o ocupante, outros que entram numa clandestinidade

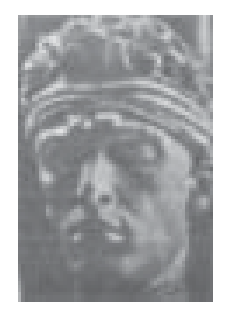
mais ou menos radical.

PALAVRAS-CHAVE:

arte, guerra, morte, memória, França.

1. Arno Brecker, sem título, 1943.

Diretor de Estudos da EHESS - Paris 
2. Picasso, O Ossário, 1944-1945.

2. Jean Fautrier, $O$ Massacre, série Reféns, 1944.
Mas o fato essencial é sem dúvida que os artistas continuaram seu trabalho. Entre os mestres já no topo das honras, Picasso não deixou de pintar, assim como tampouco Matisse ou Braque. $\mathrm{O}$ ambiente trágico do momento, entretanto, reflete-se pouco em suas obras. O Ossário (Le Charnier), que ele executou entre 1944 e 1945, não deixa sem dúvida esquecer o trabalho e o poder de Guernica, do qual se reencontra o eco.

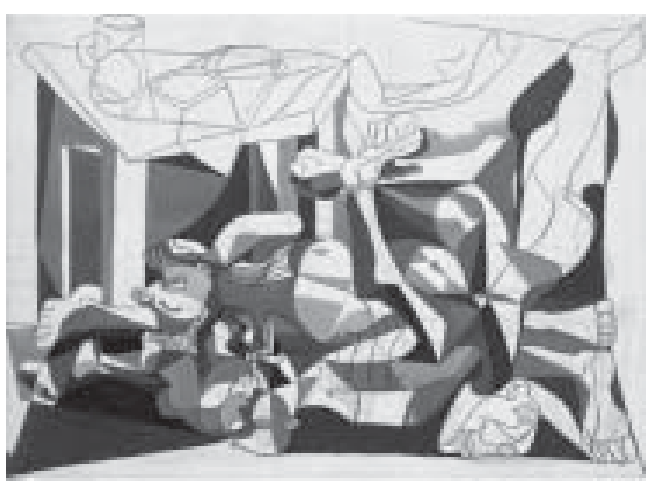

Em abril de 1944, Pignon e Fougeron fazem aparecer clandestinamente um álbum com doze litografias em proveito dos Franco-atiradores e Partidários (FTP). Mas, antes de inventar um tema que trataria diretamente da ocupação, Pignon retoma o motivo que ele tinha pintado em 1936 em Homenagem aos mineiros das Astúrias. Tudo se passa como se faltassem as forças da simbolização. Hélène Parmelin constatará desiludida em 1954: os pintores engajaram-se "dando muito de si mesmos, mas absolutamente nada de sua pintura" (Flammarion, citado em Richard, 1995, p. 190).

Aqueles que sucederão e vão representar desde então a Escola de Paris encontram-se já em maio de 1941 na exposição Vinte jovens pintores da tradição francesa na Galeria Braun, sem que o ocupante censure o acontecimento que se escondia por trás da noção de "tradição francesa" para enganar a censura.

A história imediata provoca, entretanto, rupturas na trajetória de certos artistas. Jean Hélion, geométrico abstrato antes da guerra, tenta um retorno à paisagem e reatará mais tarde com a figuração. Jean Fautrier, ao contrário, torna-se mais abstrato, e dá em 1946 a mais sensível das reações aos horrores da guerra com seu Reféns. Para tentar aproximar-se do estado

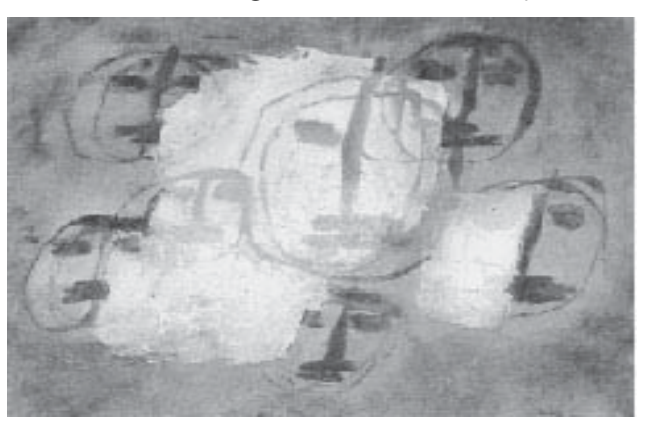

de espírito dos pintores durante esse período, é bom lembrar as palavras pelas quais Jean Paulhan descreveu essa série de telas: "Tratava-se de manter em um relâmpago da pintura moderna que se contenta, se eu posso assim dizer, com o essencial, negligencia a eloquiência, a explicação, o detalhe, e sugere mais do que justifica, (...) todos os prestígios da rica matéria, a cor preciosa e as sombras profundas e, em breve, todas as fontes da grande pintura do passado, os Ticianos e os Rubens, os Greco e os Turner. Eis o que exigiam sem dúvida as pinturas grosseiras e esses pastéis macerados, essas ${ }^{1}$ Proteção à arte (N.E.). crostas e essas espessas pinceladas, que formam enfim das torturas uma 
explosão de azul, de uma imundície sanguinolenta de lacas e fósforos, de tantos horrores, uma beleza obsessiva" (em Fautrier l'enragé).

A insistência no trabalho propriamente pictural caracteriza bem a atitude dos pintores que ficaram na França nessa época. Pignon escreverá: "durante a guerra eu tive um instrumento que era admirável contra toda aquela escuridão, era a pintura e, no fundo, é nessa pintura que se afirmava nossa recusa, nossa resistência. Durante a guerra, nossa pintura foi muito colorida por oposição à tristeza da época" (Richard, 1995).

É a cor, a matéria, os borrões, que são carregados de sentido, não o tema. Por mais espantoso que isso possa parecer, será verdadeiro também para os dramas da guerra. Sem dúvida encontram-se artistas, na liberação, que tentam figurar o horror. David Olère, que sobreviverá a seu trabalho de coveiro no forno crematório de Auschwitz, será talvez o único que tentará representar a exterminação que ele mesmo viveu nas formas da pintura: Chegada de um comboio e charrete transportando cadáveres retirados de um comboio precedente, s.d. (após 1945), Seus últimos passos, s.d. (após 1945). Alguns outros artistas deixarão desenhos que retraçam essa experiência, como Olivier Debré: O morto de Dachau (1945); Boris Tazlitzky: O pequeno campo de Buchenwald (1945) e uma série de desenhos que representam co-detidos, realizados durante sua prisão; Zoran Music: Dachau (1945); Jacques Villon: O forno crematório (1945). Para a maior parte, entretanto, essa tentativa não terá futuro, como se a pintura não fosse um meio adequado para abordar esses objetos muito violentos.

Não há lugar para alongar aqui o exame desse período contemporâneo dos acontecimentos da guerra, cujo tratamento simbólico não será ainda senão parcial e isolado. De fato, o país, ou melhor, a cultura francesa, não empreenderá uma elaboração psicológica e mental de seu comportamento durante a ocupação antes de muitos anos e não o fará com muita freqüência nas artes plásticas mas no cinema e mais geralmente no ensaio.

Existem para esse retardo circunstâncias gerais e outras particulares. Comecemos pelas segundas. Tendo apenas saído da Segunda Guerra Mundial, com a impressão enganada, graças a De Gaulle, de ter simplesmente sido uma vítima finalmente associada à vitória dos Aliados, a França entra na guerra da Indochina, substituída em breve pelos Estados Unidos, após a derrota de Dien Bien Fu, e depois na da Algéria, que terminará pelos Acordos de Evian em 1961. Essas guerras coloniais provocam na metrópole uma quase guerra civil, que recolocará mais uma vez, em 1958, De Gaulle na frente da cena política. Isso significa que durante quase vinte anos, o mundo político e cultural francês será absorvido pelas lutas (anticoloniais, anti-imperialistas) que lhe concernem diretamente, mas que têm também como resultado que o trabalho de elaboração sobre o período da Segunda Guerra Mundial e a colaboração sejam sempre adiados para mais tarde.

Num registro menos específico à França, mas que tomou apesar de tudo uma importância particular nesse país, um outro fenômeno favoreceu 
a ocultação dos problemas ligados à guerra: a força do Partido Comunista Francês $(\mathrm{PCF})$. Mestre, com os gaulistas, da rápida depuração que seguiu à liberação, o PCF estava, entretanto, enredado nas ambigüidades decorrentes do Pacto Germano-Soviético e da repressão no Goulag, ainda que esta última fosse então ainda mal conhecida. Ele tinha, portanto, todo o interesse de seguir o "consenso" nacional que dissimulava acreditar que a França tinha sido globalmente resistente (o PCF e os Gaullistas tinham-no sido igualmente), e de dirigir a atenção para o novo imperialismo norte-americano, que começava a exprimir-se fortemente na Coréia.

Ainda que sucintamente lembradas, essas circunstâncias permitem compreender que é somente a partir dos anos 60-70 que a cultura francesa começará o trabalho de anamnese sobre o período da ocupação e da guerra.

Qualquer que seja o valor dessa explicação pelas circunstâncias políticas, existem ainda muitas outras circunstâncias que é obrigatório agora examinar. O exemplo do pintor Music servirá de introdução. Sublinhei que desde 1945, Zoran Music tinha desenhado de maneira muito dramática os corpos dos deportados encontrados mortos ou vivos nos campos de concentração. Segue-se um longo período de sua obra, durante o qual esse tema não é retomado. Subitamente, nos anos 70, Music retoma o trabalho, pintando uma série de quadros muito impressionantes diretamente inspirados nos desenhos de 1945. Como compreender esse longo silêncio, que nada tem, sem dúvida, a ver com as circunstâncias lembradas acima?

Pode-se propor algumas reflexões sobre essa questão. Os mortos da guerra de 14, no imaginário francês, tinham sentido. Eles foram chorados como os heróis de uma vitória nacional, num contexto em que o tema nacionalista tinha tido uma ressonância muito forte. A França tinha lutado e tinha saído vencedora, e todo o horror das trincheiras, toda a desumanidade dessa primeira guerra técnica, não podia despojar desses mortos o sentido que eles traziam aos olhos de todos.

Os mortos da Segunda Guerra Mundial eram de uma outra natureza. $\mathrm{O}$ combate não teve lugar devido ao fato da capitulação e os milhões de mortos, judeus essencialmente, ciganos e resistentes de resto, foram todos assassinados, quando não foram mortos nos campos de horror. Eis porque, eu acredito, a questão da Verarbeitung (trans-elaboração) da guerra concentrase, na França, inevitavelmente no horror da exterminação.

Essa comparação muito rápida entre os mortos das duas guerras visa somente ressaltar um motivo essencial: por múltiplas razões, o país pôde fazer o luto dos mortos de Verdun e de Chemin des Dames. Mil monumentos aos mortos, que surgiram sobre todas as praças de todas as cidades da França após 1918, são testemunhos disso. Aqueles de 19391945, aqueles de Dachau e de Oradour-sur-Glanes não puderam verdadeiramente ser recebidos numa consciência de luto. Nada pôde elaborar (Verarbeiten) o horror, nada pôde conduzir ao que Freud chama o Trauerarbeit, o trabalho de luto (travail du deuil; work of mourning).

Preparando este texto, veio-me à memória uma frase de Roland Barthes. Ele fala da fotografia: "Quando ela é dolorosa, nada nela pode 
transformar a dor em luto" (Barthes, 1980, p. 141). A ausência de um trabalho de luto no caso dos mortos da Segunda Guerra Mundial apresentase num contexto singular, que não é mais político mas psicológico. Tudo se passa como se a exterminação em questão não existisse a nossos olhos a não ser sob a forma de fotografias. As testemunhas, tão importantes em um combate feito em conjunto, jamais existiram porque, na maior parte, elas desapareceram com aqueles dos quais elas eram as testemunhas sacrificadas, retirando do acontecimento um pouco mais do sentido do qual ele poderia revestir-se. Restando as fotografias, essas imagens que dizem com uma violência extrema o horror, mas que são, como diz ainda Barthes, "adialéticas", escapando a toda elaboração narrativa, a todo raciocínio histórico. A brutalidade irremediável que elas nos apresentam - elas nada representam - obriga-nos a "viver pela finitude da imagem", ela interdita toda catharsis.

Fotografia dos campos, sem leitura, sem explicação. Os homens e as mulheres que aí vemos permanecem como outros tantos espectros que visitam incansavelmente nossa memória. A violência de sua morte, propriamente asimbólica, não pode mais que freqüentar nossos espíritos, jamais convidá-los à lembrança. Nessas fotografias, que são talvez as fotografias por excelência porque não se vê aí nada além de uma morte exorbitada, jamais podemos reencontrar, em sua forma absoluta, mais que o escândalo da morte, a evidência de que isso teve lugar, de que "isso aconteceu".

Foi a partir dessas hipóteses que escolhi os artistas que queria comentar na segunda parte deste texto.

O primeiro é Christian Boltanski. Impossível afirmar que o trabalho deste artista trata da shoah2. Sobre a morte, sim. "Estamos enfadados com a morte, diz ele. Hoje, com a mídia, ela tornou-se uma imagem e na realidade ela é considerada como uma coisa vergonhosa. Não se morre mais, não há mais últimas palavras, cai-se em coma, somos levados ao hospital e depois, num belo dia, somos desligados. Os signos exteriores do luto, a própria idéia de monumento, desapareceram" (Boltanski, 1998).

Christian Boltanski é um artista da segunda metade do séc. XX. Sua última obra, Kaddish, tem como subtítulo: Menschlich, Sachlich, Örtlich, Sterblich. Ela concerne ao que ele chama de pequena memória. Não aquela dos monumentos e do monumental da Humanidade com h maiúsculo, mas aquela da vida cotidiana, aquela dos sem nome. O próprio dessa "pequena memória" é sua fragilidade. Ela desaparece com a morte. Essa perda de identidade é muito difícil de aceitar, diz ele, porque ela é uma igualização no esquecimento. As fotografias de Boltanski são outras tantas tentativas de salvar essa singularidade humana do esquecimento, no próprio limiar da

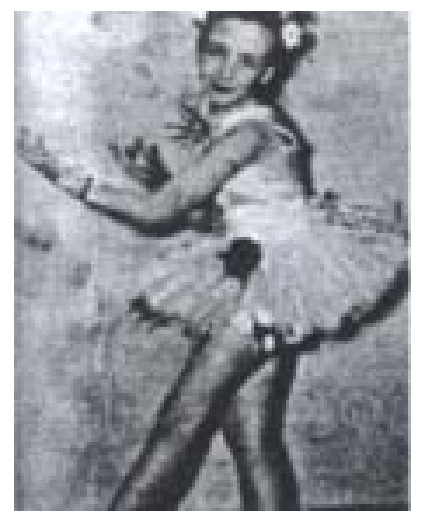

3. Boltanski, Kaddish.

${ }^{2}$ Holocausto (N.E.). 
morte. Pela fotografia, mas também por objetos que pertenceram à pessoa e que, como a fotografia, guardam dela a impressão, Boltanski erige um anti-monumento àqueles que a história não saberia reter. Nem heróis, nem criminosos, eles passam pela armadilha dos discursos que se dão as sociedades. Boltanski não faz referência aos campos de exterminação, mas essa tranqüilidade dos cemitérios da identidade, à qual ele consagra seu trabalho, inscreve-se sobre um pano de fundo que não pode, a meus olhos, senão reenviar a essa morte sem nome e sem luto possível da qual falei.

Ao generalizar para o conjunto dos humanos o anonimato daqueles que desapareceram nos campos de concentração, ao lembrar que essa desaparição é uma característica geral de nossa sociedade de massa, que é ela, por exemplo, que conduz a maior parte de seus amigos a fazer desaparecer seus corpos ao fazer-se incinerar ao invés de enterrar, Boltanski multiplica as passarelas simbólicas com o holocausto. É ele consciente disso? Trata-se de uma estratégia de sua parte a de deixar a shoah como um nãodito no horizonte de seu trabalho? Não é necessário responder a essas questões para experimentar o poder dos dispositivos que ele coloca em pé.

Essa força lança sem dúvida suas raízes na situação paradoxal que faz que a exterminação em massa de seres humanos alimente uma reflexão sobre a necessidade de preservar a memória dos sem-nome que somos. Do mesmo modo que Adorno disse que, após Auschwitz, não é mais possível "dichten", dar a forma da poesia aos acidentes do mundo, assim também, e como que em resposta, Boltanski faz que compreendamos que a fotografia, os objetos encontrados e as roupas abandonadas que ele recolhe são como o sudário de Turim, eles são a forma analógica do indivíduo que os vestiu, da mesma maneira que a fotografia atesta seu "ter sido". Com esses objetos analógicos, ele elabora a lista dos vivos, não a lista heróica de Schindler, mas uma lista sem nome, ou então, o que é equivalente, uma lista infinita de nomes, como fez na ocasião da exposição de Malmö, cujo catálogo era simplesmente o anuário de telefone da cidade.

Kaddish é um livro onde são reproduzidas sem ordem, sem hierarquia, sem respeito das funções sociais ou históricas, centenas e centenas de rostos, não retratos, mas simples suportes da vida imortalizados naquilo que eles têm de mais frágil, de mais efêmero: sua vida: Menschlich, Sanchlich, Örtlich, Sterblich, humana, concreta, aqui, mortal.

Nesse uso da fotografia, Boltanski atinge exatamente o que Roland Barthes dizia quando afirmava:

"O noema da fotografia é simples, banal; nenhuma profundidade: "isso foi". Eu conheço nossos críticos: o quê! Um livro todo (mesmo que breve) para descobrir isso que eu sei desde o primeiro lance de olhos? Sim, mas tal evidência pode ser a irmã da loucura. A Fotografia é uma evidência arrebatada, carregada, como se ela caricaturasse, não a figura que ela representa (é antes o contrário), mas sua própria existência" (Barthes, 1980, p. 176-177).

A imagem fotográfica introduz-nos a essa loucura, a essa entrada louca no espetáculo do que é a morte, daquilo que vai morrer, pela natureza 
daquilo que ela dá a conhecer (seu noema), colocando em marcha em nós, algumas vezes e como por exceção, uma música com ares antiquados à qual Barthes deu o nome de Piedade: como fez Nietzsche, quando em 3 de janeiro de 1889, atirou-se em prantos ao pescoço de um cavalo martirizado: tornou-se louco por causa da piedade.

Menschlich, Sanchlich, Örtlich, Sterblich, poder-se-ia definir assim as fotografias e os objetos coletados de Boltanski, múltiplos ao inverso daquilo que Barthes visava, talvez entretanto novamente singularizados pelo fato de que o artista se apropriou deles, que ele os arrancou em bloco do anonimato para fazer deles, não o traço de uma pessoa, mas a evidência de uma humanidade sob o olho da morte.

O que acabamos de aproximar com Barthes e Boltanski a propósito das fotografias nada tem a ver, entenda-se bem, com o espetáculo que elas mostram. Somente importa sua temporalidade, simbolizada pelo "isso foi". E essa temporalidade seria definitivamente apagada se, pela mediação do objeto, artístico ou não, um espectador não fosse convocado face a essa evanescência no tempo. É ele que ouvirá, ou não, essa música de nome antiquado: Piedade. É ele que é chamado a tomar posição, a deixar-se tocar ou não.

Esse lugar eminente de espectador no confronto com a morte, a guerra, o holocausto, determina a ação de alguns artistas que decidiram enfrentar essas questões. A partir do momento em que, face ao acontecimento em questão, o artista não está em situação de fabricar monumentos ou de figurar as respostas em objetos que têm imediatamente acesso ao ritual, desde então, ao contrário, que ele pode somente formular questões, dar à vista ou dar à palavra, porque ele mesmo não dispõe de uma linguagem afirmativa socialmente construída, o espectador não é mais uma outra pessoa à qual a obra se endereçaria como uma mensagem a um receptor. Ele é o artista ou o artista é também o espectador. Jochen Gerz formula essa idéia assim: "A crítica e a denúncia não são mais garantias de inocência. O culpável falará primeiro" . "Se eu digo 'lembrança', entendo 'esquecimento'.(...) A memória é como o sangue, acontece quando isso não se vê” . "Quando eu olho para as vítimas, eu me aproximo dos algozes" (Gerz, 1996, p. 162-163, $165,162)$.

Esta reversibilidade dos papéis que sela o destino de nossa cultura marcada pela crença no progresso e a constatação de seus impasses ou de suas contradições, o que não quer dizer de sua futilidade, colocou o tema dos efeitos perversos no centro de toda reflexão. Isso vale, assim, para a monumentalidade ligada à lembrança. A memória da guerra teria rapidamente feito conduzir a uma banalização equivalente ao esquecimento, se não se encontrassem estratégias funcionando a contrario.

Isso vale para os projetos que Jochen Gerz desenvolveu com Ester Shalev-Gerz seja para o Monumento contra o fascismo em Hamburgo, seja para o Monumento invisível de Saarbrück, seja ainda para a reconstrução do Monumento aos mortos da cidade de Biron. O conceito dessas obras é claro. O Monumento contra o fascismo (1986) é uma 
4. Jochen Gerz, Monumento (aos mortos) vivo, 19931996. coluna agora desaparecida na terra, enterrando os nomes daqueles que se associaram aos artistas para co-assiná-lo. Estes explicaram sua intenção da seguinte maneira: "Nós convidamos os cidadãos de Hamburgo, e os visitantes desta cidade, a juntar aqui seu nome ao nosso. Isso para engajar-nos a ser vigilantes e a permanecê-lo. Quanto mais numerosas forem as assinaturas sobre esta barra de chumbo de doze metros de altura, mais ela afundará no solo. E um dia, ela desaparecerá completamente e o lugar deste monumento contra o facismo estará vazio. Pois a longo termo, ninguém se elevará em nosso lugar contra a injustiça".

"O objeto não é a arte", diz Jochen Gerz. "A arte pode falar de seu próprio limite, de sua recusa de ser uma desculpa. Às pessoas que há muito dizem 'não vimos nada, não estávamos lá', o objeto responde: 'Eu tampouco estava lá'. Para que eles o reclamem. Como esse passado que eles negam. É um jogo de mimetismo. A arte veste-se de espectador" (Gerz, 1996, p. 157).

Monumento invisível, Monumento (aos mortos) vivo. Essas formulações paradoxais indicam por si

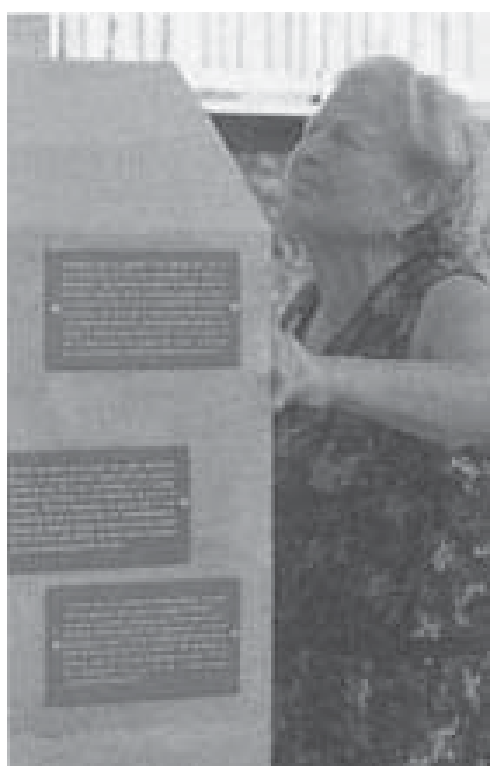
mesmas que a natureza do trabalho de luto mudou. A memória não pode, após essa guerra, condensar-se no monumental nem no ritual. É-lhe necessária uma consciência sempre renovada, despertada, viva. Donde a idéia de substituir o monumento aos mortos que ocupava uma praça de Biron, como em todos os outros lugares da França, por um monumento vivo, sobre o qual os vivos inscrevem sua própria memória, tal como esta se transforma com o tempo. O acontecimento não é mais nesse caso limitado a um "isso foi" inscrito de maneira única no tempo. Ele torna-se coextensivo à vida daqueles que ainda estão lá para relembrar-se. Ele deve sê-lo, na medida em que é a própria memória que é chamada a manter-se viva, e a colocar sempre e ainda a questão sem resposta: como aquilo que "foi", como aquilo foi possível?

A implicação do espectador, considerado aqui como memória viva, é portanto essencial a tais dispositivos. A obra, constituída materialmente de extratos de entrevistas feitas por Jochen Gertz e de fotografias realizadas durante os encontros por um fotógrafo profissional da cidade de Cahors, não se reduz a essa aparência objetual. Ela está inteiramente na própria existência das testemunhas que foram tornadas também atores da história. Como nós, os espectadores de hoje e de amanhã, o somos e o seremos ainda.

As entrevistas foram realizadas com mulheres idosas, entre 70 e 
103 anos. Elas desenrolaram-se durante o tempo do processo por "crime contra a humanidade" intentado contra Maurice Papon, antigo alto funcionário sob o Regime de Vichy, acusado de colaboração ativa. Após a guerra, entretanto, seu passado havia sido "lavado" e preenchera funções ministeriais nos anos 60 .

As fotografias dessas mulheres "Testemunhas", com uma frase tirada do que cada uma havia dito, foram afixadas em painéis publicitários na cidade de Cahors. A palavra secreta dessas testemunhas que, por sua idade e condição, pertencem àqueles que não têm em geral a palavra, foi então levada para a rua, para todos. É importante notar, contudo, que essas palavras, simples, diretas, pessoais assim como universais, não adquiriram verdadeiramente sua força a não ser porque elas apareceram no espaço público imediatamente ligadas ao rosto de quem as pronunciou. Sem essas fotografias, também elas simples e universais, sem efeitos estéticos, essas palavras ficariam abstratas, vagas, indeterminadas. A presença dos olhares dessas mulheres atesta que não somente o que elas dizem, mas aquilo do que elas foram testemunhas, "foi". E é finalmente isso que faz que essas palavras simples e leves, verba volant, tenham um peso, uma gravidade, inteiramente ligada à própria existência daqueles que as proferiram.

Gloria Friedmann realizou em 1997, para o Palácio da Justiça de Hamburgo, uma instalação que traz o título Hier, Jetzt, Aqui, agora. Ela está constituída por dois dispositivos. De um lado da construção, uma estrela em concreto, sóbria e cinza, faz referência aos anos negros: 1933-1945. Do outro, pousados sobre outros tantos tamboretes, duzentos e cinqüenta vasos de flores variadas. A artista visitou todos os empregados do Tribunal, do juiz ao pessoal de manutenção. Cada um foi convidado a associar-se pessoalmente à obra, assumindo o compromisso de manutenção de "sua" planta. Assim, o monumento ficará sempre vivo por tanto tempo quanto durar a vontade de cada um de mantê-lo enquanto tal. A memória, para exercer seu papel, deve necessariamente permanecer viva, ela depende da vontade de cada um e ninguém pode descansar sobre outros por aquilo que é sua obrigação: a vigilância.
5. Jochen Gerz,

Testemunhas, 19971998.

"Eu provoco inveja porque eu ando sem bengala. A verdade não é nada. A verdade é que eu não tenho mais ninguém. A verdade é que eu choro mais do que rio". 
KEY WORDS:

art,

war,

death,

memory,

France.
LEENHARDT, Jacques. The impossible symbolization of "that which has been". Tempo Social; Rev. Sociol. USP, S. Paulo, 12(2): 75-84, November 2000.

ABSTRACT: The author looks at the French artistic scene after the 2 nd World War, from a basic standpoint: due to a series of reasons, it was impossible for the French culture to carry out the "work of mourning" for the victims of Nazism. Based on this hypothesis, this paper analyses works that deal with life, death, violence, memory and oblivion. Because of the impossibility to condense the memory of the horror into rituals or monuments, art after Auschwitz can only formulate issues, such as the reversibility of the roles of the artist and the spectator and the historical necessity of a live memory after the scandalous, asymbolic, unnamable violence.

\section{REFERÊNCIASBIUOGRÁFICAS}

BARTHES. (1980) La chambre claire. Note sur la photographie. Paris, Cahiers du Cinéma, Le Seuil/Gallimard.

BOLTANSKI, C. (1998) Entretien avec Béatrice Parent. In: Catalogue de l'exposition "Dernières années". Musée d'art moderne de la Ville de Paris.

GERZ, Jochen. (1996) La question secrète - le monument vivant de Biron. Arles, Actes Sud.

RICHARD, Lionel. (1995) L'art et la guerre. Les artistes confrontés à la Seconde guerre mondiale. Paris, Flammarion. 